\title{
INDÚSTRIAS FARMACÊUTICAS E LICENÇA COMPULSÓRIA NO COMBATE À COVID-19: MELHOR REMÉDIO?
}

\author{
Guilherme Emmanuel Lanzillotti Alvarenga \\ Mestre em Direito Público pela Universidade Federal de Alagoas (UFAL), AL, Brasil \\ Doutorando no Programa de Pós-graduação em Sociologia e Direito da \\ Universidade Federal Fluminense, UFF, Brsil \\ guilherme56@hotmail.com \\ Maria Alice Nunes Costa \\ Pós-Doutorada em Sociologia pelo Centro de Estudos Sociais da Universidade de Coimbra (UC), \\ Coimbra, Portugal \\ Professora no Instituto de Arte e Comunicação Social e do Programa de Pós-Graduação em \\ Sociologia e Direito da Universidade Federal Fluminense (UFF), Niterói, Brasil \\ alicecosta.rj@uol.com.br
}

\section{RESUMO}

Este artigo traz à tona a questão sobre a proteção da patente de invenção no setor farmacêutico vis-à-vis ao cenário para a descoberta de medicamentos para o tratamento da COVID-19 e da vacina para conter e prevenir o seu avanço exponencial da atual pandemia global. Grandes empresas farmacêuticas têm interesse no descobrimento da terapia eficiente ao combate da COVID-19, como meio para alocar recursos financeiros e ganhar posição de destaque na concorrência internacional. Nesta competição acirrada, um dos meios de flexibilização da proteção da patente farmacêutica é a licença compulsória, na qual o Estado intervém para diminuir o preço e liberar a exploração da invenção por outros laboratórios. Demonstramos no presente que a indústria farmacêutica brasileira, carente de recursos e desenvolvimento tecnológico, terá enorme desafio para dar vazão à produção, em larga escala, de vacinas e/ou medicamentos contra a guerra viral, sem a presença do Estado. O SARS-CoV-2 veio para abalar o protagonismo das políticas neoliberais, que acreditam na pretensa alocação perfeita do mercado.

Palavras-chave: COVID-19. Patentes farmacêuticas. Licença compulsória. Brasil. Indústrias farmacêuticas.

\section{PHARMACEUTICAL INDUSTRIES AND COMPULSORY LICENSE TO COMBAT COVID-19: BETTER MEDICINE?}

\begin{abstract}
This article brings up the issue of patent protection in the pharmaceutical sector vis $a$ vis the scenario for the discovery of drugs for the treatment of COVID19 and the vaccine to contain and prevent its exponential advance from the current global pandemic. Large pharmaceutical companies are interested in discovering COVID-19's efficient combat therapy as a means to allocate financial resources and gain a prominent position in international competition. In this
\end{abstract}


fierce competition, one of the means of easing the protection of the pharmaceutical patent is the compulsory license, in which the State intervenes to reduce the price and free up the exploitation of the invention by other laboratories. We demonstrate at the present time that the Brazilian pharmaceutical industry, lacking resources and technological development, will face an enormous challenge to allow the large-scale production of vaccines and / or drugs against the viral war, without the presence of the State. The SARS-CoV-2 came to undermine the role of neoliberal policies, which believe in the supposed perfect allocation of the market.

Keywords: Covid-19. Pharmaceutical patentes. Compulsory license. Brazil. Pharmaceutical industries. 


\section{INTRODUÇÃO}

O mundo vem enfrentando a pandemia do novo coronavírus SARS-CoV-2 que já infectou mais de 6 milhões de pessoas no mundo e ceifou mais de 370 mil vidas, sem contar com os casos não notificados, devido à escassez de testagem em massa. Isso é ainda mais grave em países periféricos e semiperiféricos do sistema-mundo capitalista, na qual a infraestrutura e o saneamento básico são ínfimos e o acesso à saúde pública é deficitário.

Ao contrário, a maioria dos países centrais têm sido os protagonistas no combate ao COVID-19, na medida em que são os detentores das altas tecnologias e do capital financeiro, capazes de nortear todos os avanços científicos; enquanto que outros países, como o Brasil, possuem territórios mais pobres e são explorados pelo sistema-mundo capitalista. São espaços que foram e são colonizados pelo pensamento, pelo conhecimento, pela tecnologia e pela economia dos países centrais. As desigualdades sociais e a concentração de renda nessas regiões são abruptas, com um gap estrutural exorbitante. Neste mapa geopolítico, estas são as regiões que mais sofrem com a pandemia do COVID-19.

No meio a este caos sanitário, nasce uma corrida desenfreada da comunidade científica pela descoberta de vacina e/ou remédios eficazes no combate ou, ao menos, pelo controle da doença viral.

Importa ressaltar a importância para se atentar sobre os efeitos da dominação econômica em relação à questão patentária da descoberta de medicamentos eficazes no tratamento, em especial, quanto à criação da vacina. Dentre as grandes empresas farmacêuticas dos países centrais, há o interesse na recompensa financeira para ser a pioneira na descoberta, como meio de ganhar posição de destaque na concorrência do setor.

Nessa competição global acirrada, questionamos o papel dos Estados quanto à flexibilização da proteção da patente farmacêutica e sobre quais são os arranjos internacionais possíveis para garantir que a descoberta da vacina e/ou de medicamentos que atenuem os efeitos da doença possam ser comercializados de forma equitativamente justa, principalmente, para países que possuem estruturas frágeis no campo científico e tecnológico. Assim, a SARSCoV-2 estará testando os mecanismos das políticas neoliberais, que acreditam na pretensa alocação perfeita do mercado, na medida em que o novo coronavírus veio para nos mostrar que estamos todos interconectados e somos interdependentes. 
$\mathrm{Na}$ primeira parte, apresentamos um panorama geral do sistema das patentes farmacêuticas. Na segunda parte, apresentamos o cenário atual na busca por terapias e vacinas no combate à COVID-19, para, em seguida, trazermos uma reflexão sobre a nossa proposta quanto ao possível licenciamento compulsório às indústrias farmacêuticas, quando ocorrer a possível descoberta da vacina e/ou de medicamentos terapêuticos de combate à essa doença. Desta forma, clamamos aos leitores a questionarem: o licenciamento compulsório é remédio eficaz para produção em larga escala e amplo acesso das terapias descobertas no combate ou no controle da pandemia?

\section{SISTEMA DE PATENTES FARMACÊUTICAS}

Os "bens intelectuais" e os "produtos da mente" formam o conceito de propriedade intelectual que abrange a ideia de proteção pública para ideias, invenções e expressão criativa provenientes na maioria dos casos da atividade privada. (SHERWOOD, 1992).

O sistema de patentes serve como recompensa financeira para o inventor e, acima de tudo, como meio para estimular a pesquisa e promover o desenvolvimento tecnológico. Tratase de título de propriedade que confere a seu titular o direito de impedir terceiros de explorarem seu objeto em um território por um tempo determinado. (TOMAZETTE, 2012).

Em outras palavras, pode-se dizer que o referido sistema transforma o invento de bem tecnológico em bem econômico. Cada vez mais, o desenvolvimento das nações vincula-se ao progresso tecnológico de suas indústrias e centros de pesquisa. Os países que não possuem desenvolvimento científico e tecnológico tornam-se dependentes dessas transferências, que nada mais é do que a exportação dos resultados da pesquisa tecnológica desenvolvida por determinado país. Pimentel (1999) relata que quando se trata de adquirir tecnologia, o exportador pode reservar para si o segredo dos métodos e processos, na medida em que a fabricação é tão complexa que o importador não tem condições de produzir sozinho aquilo que adquire.

A concessão de patentes, no direito brasileiro, obedece ao disposto na Lei $\mathrm{n}$ 은 9.279/1996 (BRASIL, 1996), sendo restringida por limite temporal e territorial. O limite temporal diz respeito ao lapso de tempo em que o direito de proteção de propriedade poderá ser oposto pelo proprietário frente aos demais, evitando assim o uso indevido do objeto da proteção 
durante o período de validade. Todavia, o limite diz respeito ao território em que o direito de proteção da patente será exercido.

Inegáveis são os benefícios da preservação do direito à patente durante seu prazo legal máximo de vinte anos e da delimitação no território nacional, mas não se podem manter os benefícios do título de patente ao seu proprietário, quando este abusa desta condição e começa a influenciar o mercado para as práticas de eliminação da concorrência, bem como impedir o surgimento de novas tecnologias. (DI BLASI; GARCIA; MENDES, 2002).

Se por um lado, deve ser garantido o valor comercial dos produtos oriundos da criatividade humana; por outro, deve ser assegurado o direito de usufruto dos avanços tecnológicos que proporcionam a melhoria da qualidade de vida. Os direitos de propriedade intelectual, por esta razão, têm assumido uma figura relevante a partir da compreensão de que a proteção de tais direitos pode ser considerada um importante instrumento para o desenvolvimento econômico e social, já que a proteção das patentes é vinculada à função social que o invento deve proporcionar. Na área da saúde, a relevância da função social é a diretriz na proteção das patentes farmacêuticas ou, ao menos, deveria ser.

O acesso à saúde é uma política pública ampla, pois não basta apenas garantir o acesso ao diagnóstico, é necessário também acesso a todo o processo medicinal para garantir o tratamento e cura da enfermidade, seja ela temporária ou permanente.

Todavia, tratar do acesso à saúde como obrigação exclusiva do Estado é desconsiderar o papel da iniciativa privada nesse processo, uma vez que a produção de medicamentos e vacinas, bem como a pesquisa para a fabricação destes não são monopólios do Poder Público. Logo, como em toda atividade empresarial, o empresário do ramo farmacêutico usufrui dos benefícios inerentes ao próprio sistema de saúde, do qual faz parte a patente. Esta parceria permite lucro ao empresário e facilita o acesso dos pacientes aos medicamentos, objetos de patente, para o tratamento da saúde da população.

Portanto, deve-se buscar esclarecer a garantia do lucro da iniciativa privada e, concomitantemente, o Estado deve fomentar e incentivar a pesquisa e o desenvolvimento de novos tratamentos para as enfermidades que afligem o ser humano. Posto isso, há a necessidade de o Estado garantir aos cidadãos o acesso aos medicamentos essenciais, mesmo que, para isso, tenha de recorrer à licença compulsória e à indenização da empresa farmacêutica, atuando de forma interventiva na economia, demonstrando as características de um Estado que visa à proteção social da população. 
Desta forma, é preciso ter em mente que medicamentos essenciais à vida são questões de saúde pública. Problema relacionado à saúde pública equivale, para a ordem internacional, a uma doença que alcance uma camada relevante da população, o que acarreta, além de problema específico, uma problemática de insegurança pública. Equivale, também, à necessidade da redução de preços de medicamentos que não estejam ao alcance da condição financeira da população. (CARVALHO, 2007).

A atuação estatal ocorre por meio de políticas públicas e, ao tratar de fornecimento de medicamentos, nem sempre se torna fácil o efetivo acesso ao bem, uma vez que, devido ao título de propriedade da patente, muitas vezes o custo do medicamento torna impossível a prestação estatal e, consequentemente, não se pode falar em acesso efetivo ao sistema de saúde. (CIARLINI, 2014).

Segundo Schwartz (2004), outro fator que obsta a efetividade da política de acesso aos medicamentos reside no fato do abuso do poder econômico por parte dos agentes econômicos farmacêuticos. Seja pelo fato de impedir o desenvolvimento de novas tecnologias no setor farmacêutico ou por manter um produto essencial com preço abusivo no mercado.

A saúde não é um produto à disposição do mercado nem das bolsas de valores, mas direito fundamental e social conquistado democraticamente pela sociedade, que almeja tê-la concretizada e prestada em sua melhor forma possível pelo Estado.

Conforme Morais e Morais (1998), o direito à saúde, assegurado constitucionalmente, impõe ser pensado tanto sob o aspecto do conteúdo que o engloba quanto no acesso aos progressos tecnológicos. Embora o conceito de saúde compreenda o completo bem-estar físico, mental e social, analisa-se, no momento, o direito de acesso aos instrumentais tecnológicos desenvolvidos no âmbito das ciências médicas, sobretudo o acesso a medicamentos.

Diante das diferenças existentes, há a necessidade que os Estados adotem medidas voltadas à criação de políticas de desenvolvimento internacional, para facilitar e consolidar a plena realização do direito a uma repartição equitativa referente ao bem-estar social e econômico mundial.

A desigualdade do acesso aos medicamentos continua sendo a característica mais evidente do setor farmacêutico mundial, pois as políticas que definem o suprimento dos medicamentos, em âmbito nacional e internacional, são os principais responsáveis pelas privações e pela desigualdade extrema. (HUNT; KHOSLA, 2008). 
De acordo com relatório da Organização Mundial da Saúde (OMS), estima-se que treze milhões de pessoas morrem todos os anos, antes dos setenta anos, por doenças cardiovasculares, respiratórias crônicas, diabetes e câncer, a maioria delas em países de baixa e média renda. (WORLD HEALTH ORGANIZATION, 2018).

Assegurar a disponibilidade de medicamentos, a partir da flexibilização da propriedade intelectual, é um dos caminhos para garantir o acesso a medicamentos. Conforme Nwobike (2006), as patentes de medicamentos que concedem direitos exclusivos aos titulares das mesmas permitem que se cubra ágio sobre e acima dos custos marginais de produção, o que torna os medicamentos patenteados mais caros e acessíveis a menos clientes, em comparação com produtos similares produzidos em ambiente competitivo.

Partindo desta compreensão, existe a possibilidade de ser medido o alcance da função social da propriedade intelectual, a fim de se identificar os principais desafios e perspectivas da relação entre os direitos humanos e a propriedade intelectual. Mas nem sempre foi assim.

Desde a década de quarenta, do século passado, grandes empresas multinacionais (Big Pharma) cresceram de modo acelerado, baseadas no forte investimento em pesquisa e desenvolvimento, garantindo o lançamento de um elevado número de medicamentos inovadores e de lucros extraordinários. As indústrias farmacêuticas se fortaleceram e se expandiram com um enorme poder junto a um cenário pouco regulado pelo Estado e com baixo controle oficial de preços, beneficiando o seu ágil desenvolvimento. (PALMEIRA FILHO et al., 2012).

Com a consequente alta dos preços, na década de 1990, as gigantes farmacêuticas decidem fundir-se, a fim de diluir os riscos intrínsecos a atividades de pesquisa e desenvolvimento e aumentar o porte da empresa. Passaram a focar em um número limitado de competências, como exemplo, a escolha de determinadas classes de fármacos e, também, com a aquisição e a associação com empresas biotecnológicas de menor porte. (AKKARI et al., 2016).

Percebe-se que os próprios detentores do capital financeiro dominante passaram a regular, unilateralmente, o mercado e, principalmente, em relação à prestação do serviço de saúde, priorizando os centros de atendimento que lhes proporcionassem maior lucro, ao invés dos setores, com graves lacunas assistenciais. De acordo com Boron (2001), houve a criação de uma nova modalidade de regulação, não pelo Estado, mas pelas normas impostas pelos oligopólios que passaram a controlar os mercados e fixar regras que lhes melhor interessassem. 
No entanto, surge em 1994 o acordo sobre Aspectos dos Direitos de Propriedade Intelectual relacionados ao comércio (TRIPS), que apresenta duas características importantes: primeiro, são estabelecidas regras sobre os direitos de propriedade intelectual mais rígidas do que aquelas vigentes na ocasião nos países desenvolvidos; e, segundo, restringe a liberdade de cada país membro para adotar arcabouços legislativos, que favoreçam somente o seu desenvolvimento tecnológico.

Nesta toada, a assinatura do acordo obrigou todos os membros da Organização Mundial do Comércio (OMC) a outorgarem uma proteção mínima aos direitos da propriedade intelectual, inclusive a patente de produtos farmacêuticos, quer de países desenvolvidos ou em desenvolvimento.

Devido a essa obrigatoriedade, o acordo TRIPS provocou uma uniformização das legislações nacionais de propriedade intelectual sem, no entanto, considerar as diferenças de desenvolvimento tecnológico existentes entre os países membros da OMC. É bom ressaltar a obrigação dos Estados-membros a reconhecerem as patentes em todos os campos tecnológicos, independentemente dos aspectos sociais e econômicos que envolvam tais patentes.

Conforme o grau de desenvolvimento de cada país-membro da OMC, foi-lhe concedido um período de transição para que pudesse adequar a sua legislação de propriedade intelectual às novas disposições estabelecidas. Os efeitos da adesão ao TRIPS foram sentidos de forma diferente pelos países-signatários. Os países em desenvolvimento tiveram, indiretamente, suas oportunidades de crescimento no setor farmacêutico reduzidas (AKKARI et al., 2016). Mais uma vez, a expansão geográfica sem precedentes do capitalismo como princípio organizativo de sociedades e economias mundiais, bem como a penetração do processo de mercantilização nas diversas áreas da vida social, representaram um avanço na concentração de riquezas de uns e regresso social na de outros. (BORON, 2001).

Wallerstein (2006) afirma que Estados, empresas, famílias, classes, grupos idiossincráticos, conjuntamente, influenciam a economia e a realidade do sistema-mundo. Segundo o autor, não há a possibilidade para compreender o funcionamento do sistema de divisão em compartimento de temas como economia, política, estrutura social, cultura, uma vez que referidas categorias estão intimamente inter-relacionadas. Cada uma presume a existência da outra, afetando-se e, portanto, é incompreensível não levar em consideração esse sistema categórico. 
De acordo com o sociólogo, a realidade social é movida pelo sistema-mundo capitalista, caracterizado por uma divisão de trabalho entre os processos de produção centrais e processos de produção periféricos, distribuídos em subzonas diversas. O resultado é uma troca desigual, favorecendo aqueles que detiverem os processos de produção científicos e tecnológicos em países centrais. Desta forma, o Brasil, pertencente ao processo de produção semiperiférico, permanece sendo um dos que sofrem com o lento desenvolvimento da indústria nacional farmacêutica.

A adesão do país ao TRIPS conferiu uma severa restrição ao aumento da capacitação tecnológica nacional por meio do mecanismo learning by copying, já que a estratégia de cópia se manteve somente para a produção de medicamentos com patentes expiradas. Outra razão diz respeito à instituição do pipeline, mecanismo de pedido de patente que permitiu, nos anos de 1996 e 1997, que todo depositante que tivesse obtido uma patente, em qualquer outro país, poderia solicitá-la no Brasil, sem a necessidade de análise dos requisitos de patenteabilidade, de acordo com a legislação nacional, sendo exames técnicos adicionais apenas exigidos para inventores nacionais. Essa implementação, segundo Palmeira Filho et al. (2012), significou a concessão de patentes retroativas, aprovadas apenas pela análise formal, o que representou uma diferenciação entre inventores nacionais e estrangeiros.

A patenteabilidade dos produtos farmacêuticos elevou o preço dos medicamentos no mercado internacional, afetando uma parcela considerável da população e, consequentemente, o direito à saúde ficou prejudicado, pois diversos grupos sociais não obtiveram acesso aos medicamentos de que necessitavam (AMARAL JÚNIOR, 2005). Por esta razão, sob o ponto de vista da indústria farmacêutica internacional, a ampliação da cobertura de proteção patentária foi um dos maiores resultados do TRIPS, pois os titulares das patentes passaram a ter a possibilidade de manter altos os preços dos medicamentos patenteados, deixando-os, assim, fora do alcance de muitos países, principalmente dos mais pobres.

No tocante ao setor farmacêutico, a obrigatoriedade de conceder patentes acarretou um amplo debate internacional sobre o potencial impacto negativo que o acordo poderia ter no acesso a medicamentos, principalmente nos países periféricos. Com o objetivo de minimizar esse impacto, a OMS recomendou aos seus Estados-membros que incorporassem em suas legislações de propriedade industrial todas as flexibilidades explícitas e implícitas do acordo TRIPS relevantes para proteção da saúde pública. (CORREA, 2000). 
Ocorre, contudo, que a melhoria da saúde pública nos países em desenvolvimento depende, além do acesso a medicamentos já existentes, de consideráveis investimentos em pesquisa e desenvolvimento de novos produtos. O desenvolvimento de um novo medicamento exige um elevado grau de risco e investimentos na base de 800 milhões de dólares em investigação e desenvolvimento às empresas farmacêuticas, em um processo demorado que pode-se prolongar por mais de 15 anos, desde o início das pesquisas, até o medicamento chegar ao mercado (INSTITUTO NACIONAL DA PROPRIEDADE INDUSTRIAL, 2020). Acrescenta-se que os interesses de mercado são extremamente seletivos, pois apenas $10 \%$ do financiamento global para pesquisas vão para doenças que afetam 90\% da população do mundo. (HUNT, 2007).

Esse quadro representa a concentração das pesquisas em produtos que interessam mais aos países centrais produtores de tecnologia e não para as doenças que atacam um número maior de pessoas. Se houvesse pesquisa unicamente para os problemas típicos dos países periféricos, como tuberculose, malária, hanseníase e Mal de Chagas, os consumidores desses países não teriam condições financeiras de pagar os preços almejados pelas grandes empresas farmacêuticas. (MACEDO; PINHEIRO, 2005).

Como já bem disse Bauman (1999), todos podem desejar ser consumidor e aproveitar as oportunidades que esse estilo de vida fornece, mas nem todos podem ser assim considerados, na medida em que não basta somente desejar, deve-se ter uma esperança racional de chegar mais perto do objeto desejado para assim desfrutá-lo. Com a presença da autorregulamentação do mercado, essa esperança fica cada vez mais longínqua.

Segundo Macedo e Pinheiro (2005), os números concretos exemplificam a situação de segmentação de mercado: “Dos 1.220 medicamentos produzidos entre 1975 e 2000, somente 11 eram destinados a combater doenças tropicais", sendo que "apenas $0,2 \%$ das pesquisas foram orientadas para o combate da tuberculose e diarreia, que atingem $18 \%$ do total dos doentes no terceiro mundo." (VARELLA, 2005, p. 176-177).

Dessa forma, embora os países desenvolvidos defendam a tese de que o respeito aos direitos de propriedade intelectual seria o instrumento impulsor das atividades de pesquisa e desenvolvimento de novos medicamentos, não é o que está ocorrendo. Não há a propagada "repartição de benefícios", na medida em que a indústria farmacêutica não tem interesse em aplicar recursos na investigação de novos medicamentos para doenças prevalecentes nos países em desenvolvimento. 
A tendência exclusivista da indústria farmacêutica continua durante o atual século. Pesquisa realizada por Akkari et al. (2016), a partir de levantamento de dados realizados na Organização Mundial de Propriedade Intelectual (OMPI) demonstrou 556.122 patentes na categoria Pharmaceuticals concedidas à Europa, aos EUA, à China, à Índia e ao Brasil, entre 1996-2013. Verificou-se que a maior parte das patentes de produtos/processos farmacêuticos concentram-se nos EUA (22,79\%) e na Europa $(29,26 \%)$, sendo que a Alemanha, a França, o Reino Unido e a Suíça são responsáveis por, aproximadamente, $57 \%$ do índice europeu. O ranking mundial segue com a China $(7,09 \%)$ e com o Japão $(6,03 \%)$, demonstrando que o ritmo de crescimento chinês permitiu que o país ultrapassasse o índice japonês, sempre considerado um líder mundial no setor ao lado do europeu e do norte-americano. Bem mais abaixo, constatou-se o índice indiano, correspondente a 0,67\%; enquanto o Brasil, foi responsável por somente $0,06 \%$ das patentes farmacêuticas no mundo.

Mais recentemente, através de consulta ao Instituto Europeu de Patentes, verificou-se a evolução de 166.594 (2017) para 174.481 (2018) e para 181.406 (2019), com os países europeus a contribuírem, com aproximadamente metade dos pedidos de patente em nível global (45\%); seguidos dos Estados Unidos (25\%); Japão (12\%); China (7\%); República da Coreia (5\%); e, outros países (6\%), (EUROPEAN PATENT OFFICE, 2019). O que nos confirma a hegemonia dos países centrais no monopólio patentário. De todo modo, é importante mencionar que muitos países, hoje desenvolvidos, optaram durante anos pela não concessão de patentes, enquanto suas bases industriais e tecnológicas não estivessem consolidadas, objetivando, com isso, a proteção da saúde pública de sua população. Um deles é o Japão, que se valeu de um regime de baixa proteção à propriedade intelectual, que permitia a cópia, enquanto suas indústrias se desenvolviam. (GUISE, 2007).

Outra região, considerada potência mundial ao lado dos Estados Unidos, é a China. Com a adesão ao TRIPS causou efeitos muito mais positivos e harmoniosos para o país, quando comparado ao Brasil, uma vez que, antes mesmo de assinar o acordo, já havia aplicado mudanças em sua legislação de propriedade industrial, visando atrair investimentos externos e favorecer o acesso chinês a novas tecnologias existentes nos países desenvolvidos (AKKARI et al., 2016). Foi sob essa perspectiva e com uma postura do governo chinês inclinada ao impulsionamento da inovação, que o país aumentou seu nível de proteção intelectual de maneira diferenciada a de outros países em desenvolvimento, além de ter optado em não conceder patentes retroativas. 
Assim, além do questionável grau de favorecimento que o sistema de patentes traz para os países em desenvolvimento, em matéria de transferência de tecnologia, estes também sofrem com os efeitos negativos das normas, representados pelo alto preço dos produtos protegidos, o que se torna extremamente perverso para a saúde pública, principalmente quando se trata de produtos farmacêuticos. (CAVALCANTE, 2007).

E o Brasil não é diferente. Os dados obtidos por Akkari et al. (2016) indicam o reduzido poder de inovação do setor farmacêutico nacional, quando comparado aos países europeus, aos EUA e a outros países farmaemergentes, como China e Índia, sendo um reflexo da estratégia das empresas brasileiras fabricantes de medicamentos de se especializar, majoritariamente, na produção de genéricos.

Segundo Frenkel (2002), o baixo nível de inovação tecnológica da indústria brasileira de produtos farmacêuticos deve-se ao fato de essa, na cadeia de valor, concentrar-se principalmente nas atividades de produção de medicamentos (especialmente aqueles com patentes expiradas) e marketing. Isso significa que atividades mais intensivas em ciência e tecnologia e, com maior poder de conferir um diferencial competitivo, como pesquisa e desenvolvimento, não foram introduzidas e assimiladas no setor produtivo brasileiro, demandando competências ainda pouco presentes na indústria de medicamentos do Brasil.

Há, portanto, necessidade de desenvolvimento de políticas industriais e tecnológicas mais audaciosas para o Brasil, como a formação de parcerias público-privadas, a descentralização das atividades de pesquisa e desenvolvimento e a aquisição de competências e conhecimentos tecnológicos já consolidados pelos países líderes.

Benetti (2007) afirma que a função da patente de medicamentos é bastante questionável e paradoxal, no sentido de que resta evidente a insuficiência conceitual do próprio termo patente. Para esse autor, não há como compreender um sistema que assegura direito de exploração sobre aquilo que é considerado um bem coletivo: "Como tratar a apropriação para fins de exploração comercial, do conhecimento científico e tecnológico ligado à preservação da vida ou da saúde humana?" (BENETTI, 2007, p. 346-347).

Dessa forma, não há como negar a peculiaridade das patentes farmacêuticas. Por isso, Macedo e Pinheiro (2005) defendem que as patentes farmacêuticas devem ser encaradas pela essencialidade dos objetos que protegem. Logo, mesmo que o Estado brasileiro não monopolize a atividade de produção e comercialização de medicamentos, o que significa atuar de forma direta na economia, a participação do Poder Público, nesse caso, ocorre de forma 
indireta, pela intervenção e regulação do mercado, com escopo de evitar o abuso de poder econômico.

Arnaud (1999) revela que o direito possui o poder de coerção de que dispõe o Estado para exercer o controle que a ele pertence. Ressaltando que a regulação social não se pode libertar das disposições jurídicas fundamentais que definem o caráter público da ação, repartição dos papéis institucionais e legitimidade das autoridades de decisão e de controle. E como o debate sobre as patentes farmacêuticas tem como fim a saúde individual e coletiva, encontra-se latente o interesse social em questão, legitimando a intervenção estatal, notadamente, em épocas de calamidade pública, crises sanitárias e econômicas, como a que vivemos, hoje, com a pandemia do novo coronavírus.

Diante do atual cenário desta pandemia, é preciso questionar: Em face a nossa dependência tecnológica em relação aos países centrais, notadamente, na área farmacêutica, como o Brasil irá enfrentar a busca por vacinas e medicamentos na prevenção e combate à COVID-19?

\section{BUSCAS POR TERAPIAS EFICIENTES CONTRA A COVID-19}

A COVID-19 (Coronavirus Disease) é o nome da doença originada pelo novo Coronavírus SARS-CoV-2, cujos sintomas são infecção respiratória aguda, febre, tosse e falta de ar. Nos casos mais graves pode causar pneumonia grave com insuficiência respiratória aguda, falência renal e de outros órgãos e, eventualmente, a morte. O vírus SARS-CoV-2 foi identificado pela primeira vez em dezembro de 2019 em Wuhan, China, e sua fonte de infecção permanece desconhecida. (MINISTÉRIO DA SAÚDE, 2020).

Pelo fato de ser um vírus novo, cientistas pesquisam sobre suas formas de transmissão, sabendo-se, no entanto, que a contaminação se dá através das mucosas decorrente de contatos próximos com pessoas infectadas ou da exposição a superfícies contaminadas. Devido a sua alta contagiosidade e relevante mortalidade, com cerca de $15 \%$ dos pacientes com COVID19 sofrendo de doenças graves e sobrecarregando os sistemas público e privado de saúde, os tratamentos são desesperadamente necessários. Para se ter uma ideia, no fim de maio de 2020, já há mais de 6 milhões de contaminados no mundo, com 370 mil mortes (IMPERIAL COLLEGE LONDON, 2020), sem contar com os casos subnotificados pela escassez de testes comprobatórios. 
Em vista da catastrófica situação vivida atualmente pela sociedade mundial, em que não há tratamento preventivo, nem tampouco curativo da doença, só tem nos restado medidas paliativas para conter ou, ao menos, desacelerar o contágio, como o isolamento social (WORLD HEALTH ORGANIZATION, 2020). A OMS anunciou, recentemente, grande estudo global, chamado SOLIDARITY, para desvendar como se podem tratar infecções do novo coronavírus.

Há pesquisas de medicamentos ainda não aprovados em humanos, que tiveram bom desempenho em estudos com animais, como os outros dois coronavírus mortais, que causam síndrome respiratória aguda grave (SARS) e síndrome respiratória do Oriente Médio (MERS). Os cientistas sugeriram dezenas de compostos existentes para testes, porém, a OMS está se concentrando em quatro terapias mais promissoras: i) um composto antiviral experimental chamado Remdesivir; ii) os medicamentos contra a malária: Cloroquina e Hidroxicloroquina; iii) uma combinação de dois medicamentos para o HIV, Lopinavir e Ritonavir; iv) e a mesma combinação mais Interferon-Beta, um mensageiro do sistema imunológico que pode ajudar a paralisar os vírus. (KUPFERSCHMIDT; COHEN, 2020).

Com relação à prevenção ao vírus, há em curso seis vacinas contra a COVID-19, que já iniciaram testes com humanos no mudo, conforme levantamento da BBC News (NAVAS, 2020). A vacina mRNA-1273 da Moderna Therapeutics (Estados Unidos), empresa de biotecnologia de Massachusetts, nos Estados Unidos, cujo objetivo é "treinar" o sistema imunológico do indivíduo para gerar uma resposta para combater o vírus e prevenir doenças.

Outra pesquisa norte-americana é a vacina INO-4800 da Inovio Pharmaceuticals, da empresa de biotecnologia da Pensilvânia, focada na injeção direta de DNA, cultivado por cientistas $^{8}$. Saliente-se que ambas as empresas norte-americanas estão utilizando novas tecnologias, que envolvem a modificação ou manipulação de material genético.

Do lado asiático, na corrida entre potências mundiais para se encontrar terapia preventiva ao novo coronavírus, há a pesquisa da vacina AD5-nCoV da CanSino Biologics, empresa chinesa de biotecnologia em colaboração com o Instituto de Biotecnologia e a Academia de Ciências Médicas Militares da China. Utiliza-se de uma versão de um adenovírus (o vírus que causa o resfriado comum) como vetor. De acordo com os estudos, esse vetor transporta o gene da proteína da superfície do coronavírus e, assim, tenta provocar a resposta imune para combater a infecção.

8 O coronavírus só tem RNA. Desta forma, os cientistas precisam cultivar o DNA com a ajuda de estruturas bacterianas chamadas plasmídeos no interior das nossas células, de forma que elas produzam anticorpos para combater a infecção. 
Outra candidata chinesa é a vacina LV-SMENP-DC do Instituto Médico Genoimmune de Shenzhen, cuja proposta é usar células dendríticas (leucócitos que protegem o corpo de antígenos) modificadas por meio de vetores lentivirais (método pelo qual genes podem ser inseridos, modificados ou eliminado em organismos) para buscar uma resposta imune.

Há também a vacina do Instituto de Produtos Biológicos de Wuhan, subordinada ao Grupo Farmacêutico Nacional da China, Sinopharm, terceira candidata do país asiático, cujo projeto é uma vacina de vírus inativado, feita de partículas do vírus, bactéria ou outros patógenos cultivados, sem capacidade de provocar doenças. Utiliza-se de tecnologia que possui produtos que já estão licenciados e comercializados.

Por fim, direcionando-se ao eixo europeu, onde há a vacina ChAdOx1 do Instituto Jenner, Universidade de Oxford no Reino Unido. A proposta é uma vacina semelhante à da empresa chinesa CanSino, usando uma versão atenuada de um adenovírus, vírus comum de resfriado responsável por causar infecção em chimpanzés. O vírus foi alterado geneticamente para que não cresça em humanos.

No Brasil, há ao menos duas pesquisas promissoras, com linhas diferentes. Em São Paulo, o Instituto do Coração do Hospital das Clínicas da Faculdade de Medicina da USP (INCOR) iniciou os estudos em fevereiro e já faz os primeiros testes em camundongos. Outro estudo está nas mãos de cientistas da Universidade Federal de Minas Gerais (UFMG). No entanto, os pesquisadores brasileiros trabalham com um horizonte de dois a três anos para que a vacina nacional esteja disponível. (CRUZ, 2020).

Há de se considerar que o custo elevado de pesquisa e desenvolvimento é reflexo do longo período necessário para o desenvolvimento de um novo composto, podendo alcançar treze anos até a formulação farmacêutica chegar ao mercado, associado a taxas baixas de sucesso, sendo que a cada 10.000 moléculas utilizadas nos estágios iniciais da pesquisa, apenas uma consegue chegar à fase de comercialização. (AKKARI et al., 2016).

O elevado custo aliado aos potenciais riscos de fracassos, o domínio tecnológico e de recursos alocados são fatores atuais que lançam na frente os países centrais junto com a China, na corrida em busca de terapia preventiva no combate ao coronavírus.

Pois bem, encontrando-se a vacina ou o medicamento eficaz ao combate a COVID-19, o inventor tem total direito em requerer a patente farmacêutica do seu invento. Fato que pode gerar elevados custos para aquisição da terapia no nível global, já que deterá o monopólio temporário da invenção, podendo cobrar a seu bel-prazer o royalty para utilização. Este é o 
nosso atual desafio mundial, frente a um vírus altamente contagioso e, por vezes, letal, principalmente em regiões e comunidades que vivem sob vulnerabilidade socioeconômica. Frente a isto, como os países irão proceder, a fim de que o registro da patente da vacina não seja um empecilho a sua grande produção e ampla distribuição às sociedades?

\section{LICENCIAMENTO COMPULSÓRIO DA TERAPIA FARMACÊUTICA}

A licença compulsória está prevista no ordenamento jurídico brasileiro, na Lei 9.279 de 1998 e no ordenamento jurídico internacional (acordo TRIPS), assinado pelo Brasil em 1994, que utilizou a expressão "outros usos sem autorização do titular da patente".

Trata-se de autorização governamental que permite a exploração por terceiros de um produto ou processo patenteado, sem o consentimento do titular da patente. Uma licença compulsória somente poderá ser emitida em circunstâncias próprias, ou seja, mediante algumas condições como: abuso do poder econômico, falta de exploração da patente, interesse público, situações de emergência nacional e extrema urgência, para remediar práticas anticompetitivas e de concorrência desleal, por falta de produção local e na existência de patentes dependentes.

Nos casos em que ocorrer o abuso do poder econômico das empresas farmacêuticas, deve o próprio Estado negociar a licença compulsória, em que o Poder Público estabelece as regras de utilização e negociação da patente, garantindo não somente o acesso ao medicamento, como também a regulação do mercado, com o escopo de impedir a perpetuação de atos que venham a impedir o desenvolvimento de novas tecnologias e represente uma dominação de mercado contra a livre concorrência e a livre iniciativa. (DI BLASI; GARCIA; MENDES, 2002).

Algumas indústrias farmacêuticas argumentam que, à medida que uma licença compulsória reduz os preços dos produtos patenteados e dos lucros do proprietário da patente, também reduz os incentivos para a pesquisa e desenvolvimento de novos produtos.

Carvalho (2007) entende que a solução para o acesso a medicamentos essenciais não deve se dar na órbita privada e, sim, através do investimento na pesquisa e desenvolvimento dos laboratórios públicos, sob a responsabilidade do Estado. A licença compulsória não se presta a sanar a insuficiência da indústria nacional, mas sim sanar situação de emergência em relação à saúde pública, como elemento primordial da proteção internacional aos interesses 
sociais. Seu uso excessivo pode ser muito efetivo no curto prazo, mas no longo, é capaz de produzir efeitos trágicos sobre a saúde pública, devido às reduções na pesquisa e no desenvolvimento de novos fármacos pelo setor privado.

Em contrapartida, o não reconhecimento de patentes para o setor farmacêutico, acompanhado de uma política de desenvolvimento industrial nacional, possibilita o fortalecimento de parques industriais locais, contribuindo para a diminuição da dependência tecnológica e econômica, importante característica do setor farmacêutico nos países em desenvolvimento. (BERMUDEZ; OLIVEIRA; CHAVES, 2004).

O Brasil, em 04 de maio de 2007, decretou pela primeira vez a licença compulsória de uma patente do medicamento de combate à AIDS, Efavirenz, fabricado pelo laboratório americano Merck Sharp \& Dohme. Isso depois de um embate que começou em janeiro de 2004, quando o Ministério da Saúde conseguiu reduzir o preço de cinco medicamentos de combate à AIDS (Nelfinavir, Lopinavir, Efavirenz, Tenofovir e Atazanavir), representando uma redução de $37 \%$ no valor dos antirretrovirais. Em outro embate, em julho de 2005, o Ministério da Saúde emite comunicado sobre a conclusão da negociação com o laboratório Abbott, fabricante do antirretroviral Kaletra, garantindo a redução do preço do medicamento e o acesso à nova formulação e transferência de tecnologia. (GONZATTO; LISBOA, 2007).

O instrumento voltou ao centro do debate, a partir das propostas dos projetos de lei: PL no 1184/2020 (BRASIL, 2020a), PL no 1320/2020 (BRASIL, 2020b) e PL no 1462/2020 (BRASIL, 2020c), em que se propõe a concessão de licença compulsória para a exploração da patente em casos de emergência nacional ou interesse público, trazendo também regras específicas para o tratamento da COVID-19.

E nos perguntamos: Será que a licença compulsória, popularmente denominada "quebra de patentes", será a solução quando encontrada a vacina ou medicamento no combate ao novo coronavírus?

Há de se atentar que o Brasil está longe de deter o arcabouço tecnológico e recursos necessários para pesquisa e desenvolvimento na área farmacêutica, em comparação com os países centrais europeus e os Estados Unidos. De nada adiantaria o uso da licença compulsória do Estado brasileiro se o país não tiver capacidade de produção de produtos farmacêuticos, até mesmo os genéricos, principalmente em larga escala. O que será necessário, agora, para o combate à COVID-19, estando, inclusive, as próprias indústrias farmacêuticas estrangeiras 
questionando-se em como dar vazão de produção e distribuição em larga escala e em tempo recorde a vacinas e/ou medicamentos.

Ressalte-se que a contagiosidade do novo coronavírus é bem mais alta do que pelo HIV. A demanda por terapias de luta contra a COVID-19 será bem mais elevada do que a AIDS, uma vez que a contagiosidade do SARS-CoV 2 cresce em nível exponencial.

Talvez, a solução fosse a realização de acordos comerciais que passem pela importação de medicamentos. Mas não é tão fácil assim... Seria necessária uma concertação em esfera transnacional.

Na corrida da proteção patentária, o governo norte-americano concedeu à grande empresa farmacêutica Gilead Sciences o direito exclusivo de lucrar com o Remdesivir, um medicamento que ela desenvolveu e que pode ser útil no tratamento da COVID-19. A concessão baseou-se em legislação criada para ajudar no combate a "doenças raras", que acaba por ter efeito o bloqueio de fornecimento de medicamentos antivirais de fabricantes de medicamentos genéricos e maior proporção lucrativa para a farmacêutica. A Lei de Medicamentos Órfãos de 1983 oferece incentivos especiais às empresas farmacêuticas para fabricar produtos que tratam doenças raras, com o período de sete anos de exclusividade de mercado, concessões e créditos fiscais de $25 \%$ do custo dos testes clínicos de medicamentos. (FANG; LERNER 2020).

Acaso o Remdesivir seja, de fato, confirmado como medicamento para tratamento da Covid-19, seu custo será altíssimo, já que a Gilead Science detém, pelo período de sete anos, o uso exclusivo da patente e da produção do fármaco por outras farmacêuticas. Só poderá ocorrer produção de outra indústria, caso houver anuência da inventora, que detém, inclusive, o monopólio da negociação do royalty a ser eventualmente cobrado.

Contrapondo-se a conduta da Gilead Science, empresas farmacêuticas, como a AbbVie Inc., em relação ao seu medicamento Kaletra ${ }^{9}$, já se disponibilizaram, por livre iniciativa, a abdicar de direitos de exclusividade das patentes relativas a esse medicamento. Paralelamente, surgem ações como o Open Covid Pledge, nos EUA, que visa pressionar o setor público e privado no sentido de dispensarem dos direitos de propriedade industrial, inerentes às suas invenções, durante o atual estado pandêmico. (SERRANO; PINHO, 2020).

Os Ministérios da Saúde do Canadá e da Alemanha avaliam a concessão de isenção temporária de licenças para empresas que necessitem de recorrer a tecnologias patenteadas,

\footnotetext{
${ }^{9}$ Que utiliza a combinação de dois antivirais: lopinavir e ritonavir.
} 
especificamente no caso da COVID-19, sendo que o titular da patente será necessariamente remunerado pelos respectivos Estados. (MAIA, 2020).

Essa linha de flexibilização do direito de uso das patentes farmacêuticas vem ganhando força, através de apelos internacionais pela divulgação de dados, pesquisa e tecnologias. O presidente da Costa Rica sugeriu a OMS a realização de levantamento de tecnologias úteis para a deteç̧ão, prevenção, controle e tratamento da COVID-19, que até então estão protegidas por propriedade industrial, objetivando seu compartilhamento para as que tivessem existido financiamento público, na qual a assinatura seria um ato voluntário. (SILVERMAN, 2020).

Por sua vez, a OMPI inaugurou funcionalidade na sua plataforma de pesquisa de documentos de patente PATENTSCOPE, a qual fornecerá a cientistas e agentes envolvidos nas políticas de saúde pública, membros da indústria e do público em geral, uma fonte acessível para melhorar a identificação, prevenção e tratamento de doenças como a COVID-19. (WORLD INTELLECTUAL PROPERTY ORGANIZATION, 2020).

As Nações Unidas apoiam projeto de resolução de cooperação internacional para garantir o acesso global a medicamentos, vacinas e equipamentos médicos no enfrentamento da COVID-19. (BUSS; GALVÃO, 2020).

Como diria Wallerstein (2006), a "evolução" do desenvolvimento econômico, científico e tecnológico não é linear no sistema-mundo capitalista. Sua transformação ocorre por meio de ciclos históricos, que serão moldados de acordo com as necessidades e influências de todo o contexto que deu origem ao sistema. Vê-se na atualidade que os próprios detentores dos processos produtivos centrais estão diante de conflito dentro do sistema-mundo, os quais ainda não foram capazes de resolver. Há regiões que priorizam o protagonismo da economia no sistema, enquanto outros abdicam, mesmo que de forma temporária, a prevalência dessa na corrida pela fórmula de combate ao novo coronavírus. Enquanto isso, os países de processos produtivos periféricos lutam contra o tempo, com todas as dificuldades oriundas da falta de tecnologia avançada e recursos, para alcançar o sonhado tratamento e/ou a prevenção da COVID-19.

\section{CONSIDERAÇÕES FINAIS}

Analisando o cenário mundial de "caça" por uma terapia eficaz no tratamento da COVID-19, verifica-se um mix de interesses de indústrias farmacêuticas e dos Estados na 
prevenção e recuperação em saúde, no combate ao novo coronavírus. De um lado, busca-se a retomada dos investimentos em pesquisa e desenvolvimento de vacinas e remédios e, por outro, vislumbra-se os próprios lucros e a visibilidade e os holofotes para o pioneirismo na descoberta da "cura".

A proteção patentária da invenção seja de primeiro uso ou de segundo uso, quando há a utilização de fármaco já existente para outro fim ainda não descoberto, deve ser levada em conta o fomento em pesquisas e desenvolvimento de tecnologias farmacêuticas. Hoje, o centro das atenções é o SARS CoV-2, mas amanhã, pode ser outro vírus ou bactéria, muito mais contagioso e letal.

A razão de existir das indústrias farmacêuticas é a preservação da vida e a promoção do bem-estar do ser humano. De nada adianta preocupar-se em desenvolvimento tecnológico, se vidas estão sendo ceifadas, por mal ainda desconhecido.

A licença compulsória, específica para a COVID-19, pode até ser uma aliada ao combate à pandemia, mas geram dúvidas sobre o fôlego da indústria farmacêutica brasileira, carente de recursos e desenvolvimento tecnológico, para ser capaz de dar vazão à produção em larga escala em pouco tempo de vacinas e/ou medicamentos contra a guerra viral, sem auxílio do Estado.

A presença estatal é de fundamental importância seja na decretação de licença compulsória, com a alocação de recursos e logística à indústria nacional na produção da terapia em larga escala, seja na definição do preço junto ao inventor.

Acreditamos que é a partir do diálogo internacional dirigido ao convencimento da empresa pioneira para realizar a licença voluntária e a utilização da invenção a preços módicos, com compartilhamento das informações junto à comunidade científica. Este será o exemplo de cooperação internacional pelo uso do bem comum da medicina, neste nosso período pandêmico.

Nessa guerra pela vindoura patente farmacêutica pioneira na vacina eficaz contra o novo coronavírus, que apresentamos questionamentos e propostas neste artigo, no intuito de, pelo menos, reduzir os efeitos negativos nos países semiperiféricos e periféricos, que, certamente, correm bem atrás no acesso a tão esperada terapia.

Remédio? Ainda não temos. 


\section{REFERÊNCIAS}

AKKARI, A. C. S. et al. Inovação tecnológica na indústria farmacêutica: diferenças entre a Europa, os EUA e os países farmaemergentes. Gestão e Produção, São Carlos, v. 23, n. 2, p. $365-$ 380, 2016. DOI 10.1590/0104-530x2150-15. Disponível em:

https://www.scielo.br/scielo.php?script=sci_arttext\&pid=S0104-

530X2016000200365\&lng=en\&nrm=iso. Acesso em: 31 maio 2020.

AMARAL JÚNIOR, Alberto do. Licença compulsória e acesso a medicamentos nos países em desenvolvimento. Revista do Instituto dos Advogados de São Paulo, São Paulo, v. 8, n. 16, p. 11-23, 2005.

ARNAUD, André-Jean. $\mathbf{O}$ direito entre modernidade e globalização: lições de filosofia do direito e do estado. Tradução: Patrice Charles Wuillaume. Rio de Janeiro: Renovar, 1999.

BAUMAN, Zygmunt. Globalização: as consequências humanas. Rio de Janeiro: Zahar, 1999.

BENETTI, Daniela Vanila Nakalski. Proteção às patentes de medicamentos e comércio internacional. In: BARRAL, Welber; PIMENTEL, Luiz Otávio. Propriedade intelectual e desenvolvimento. Florianopolis: Fundação Boiteux, 2007. p. 329-358.

BERMUDEZ, J. A. Z.; OLIVEIRA, M. A.; CHAVES, G. C. O acordo TRIPS da OMC e os desafios para a saúde pública. In: BERMUDEZ, J. A. Z.; OLIVEIRA, M. A.; ESHER, A. Acceso a medicamentos: derecho fundamental, papel del estado. Rio de Janeiro: Escola Nacional de Saúde Pública: Fundação Oswaldo Cruz, 2004. p. 69-90.

BORON, A. A. El nuevo orden imperial y cómo desmontarlo. In: SEOANE, J. et al. Resistencias mundiales: [de Seattle a Porto Alegre]. Buenos Aires: CLACSO, 2001. p. 31-62.

BRASIL. Lei no 9.279, de 14 de maio de 1996. Regula direitos e obrigações relativos à propriedade industrial. Brasília, DF: Presidência da República, 1996. Disponível em: http://www.planalto.gov.br/ccivil_03/Leis/L9279.htm. Acesso em: 29 maio 2020.

BRASIL. Projeto de Lei no 1184, de 27 de março de 2020. Dispõe sobre a concessão das licenças não-voluntárias prevista na Lei ${ }^{\circ} 9.279$, de 14 de maio de 1996, que regula direitos e obrigações relativos à propriedade industrial. Brasília, DF: Câmara dos Deputados, 2020a. Disponível em:

https://www.camara.leg.br/proposicoesWeb/prop_mostrarintegra?codteor $=1871257 \&$ filenam e=PL+1184/2020. Acesso em: 30 maio 2020.

BRASIL. Projeto de Lei no 1320, de 31 de março de 2020. Altera o art. 71 da Lei no 9.279, de 14 de maio de 1996, para tratar de licença compulsória nos casos de emergência nacional decorrentes de declaração de emergência de saúde pública de importância nacional ou de importância internacional. Brasília, DF: Câmara dos Deputados, 2020b. Disponível em: https://www.camara.leg.br/proposicoesWeb/prop_mostrarintegra?codteor=1871991\&filenam e=PL+1320/2020. Acesso em: 30 maio 2020. 
BRASIL. Projeto de Lei no 1462, de 2 de abril de 2020. Altera o art. 71 da Lei no 9.279, de 14 de maio de 1996, para tratar de licença compulsória nos casos de emergência nacional decorrentes de declaração de emergência de saúde pública de importância nacional ou de importância internacional. Brasília, DF: Câmara dos Deputados, 2020c. Disponível em: https://www.camara.leg.br/proposicoesWeb/prop_mostrarintegra?codteor=1872758\&filenam $\mathrm{e}=\mathrm{PL}+1462 / 2020$. Acesso em: 30 maio 2020.

BUSS, Paulo; GALVÃO, Luiz Augusto. Assembleia Mundial da Saúde: equidade na resposta à pandemia? Centro de Estudos Estratégicos da FIOCRUZ, Rio de Janeiro, 2020. Disponível em: https://cee.fiocruz.br/?q=node/1183. Acesso em: 29 maio 2020.

CARVALHO, Patrícia Luciane de. Patentes farmacêuticas e acesso a medicamentos. São Paulo: Atlas, 2007.

CAVALCANTE, Milene Dantas. Patentes de medicamentos e as políticas de desenvolvimento: estudo de caso da controvérsia entre Índia e Estados Unidos. In: BARRAL, Welber; PIMENTEL, Luiz Otávio. Propriedade intelectual e desenvolvimento. Florianopolis: Fundação Boiteux, 2007. p. 381-409.

CIARLINI. A. L. A. S. Direito à saúde: paradigmas procedimentais e substanciais da constituição. São Paulo: Saraiva, 2014.

CORREA, C. M. Integrating public health concerns into patent legislation in developing countries. Geneva: South Centre, 2000.

CRUZ, Marcia Maria. Covid-19: brasileiros desenvolvem 2 das vacinas que o mundo busca: os trabalhos em curso nos laboratórios da federal de Minas estão à frente das iniciativas para imunização consideradas mais promissoras contra a COVID-19. Correio Braziliense, [S. I.], 2020. Disponível em: https://www.correiobraziliense.com.br/app/noticia/ciencia-esaude/2020/05/17/interna_ciencia_saude,855794/covid-19-brasileiros-desenvolvem-2-dasvacinas-que-o-mundo-busca.shtml. Acesso em: 30 maio 2020.

DI BLASI, G.; GARCIA, M. S.; MENDES, P. P. M. A propriedade industrial: os sistemas de marcas, patentes e desenhos industriais analisados a partir da Lei número 9.279 , de 14 de maio de 1996. Rio de Janeiro: Forense Universitária, 2002.

EUROPEAN PATENT OFFICE. Trends in patenting 2019. European Patent Office, [S. I.], 2019. Disponível em:

http://documents.epo.org/projects/babylon/eponet.nsf/0/26767BC3D0AEB95AC12585230035 9E0E/\$FILE/epo_patent_index_2019_infographic_en.pdf. Acesso em: 30 maio 2020.

FANG, Lee; LERNER, Sharon. Coronavirus treatment developed by gilead sciences granted "rare disease" status, potentially limiting affordability. The Intercept, [S. I.], 2020. Disponivel em: https://theintercept.com/2020/03/23/gilead-sciences-coronavirus-treatment-orphan-drugstatus/. Acesso em: 30 maio 2020.

FRENKEL, J. Cadeias em que predomina o comércio intrafirma: farmacêutica. In: MORAES, Márcia Azanha Ferraz Dias de; NASSAR, André Meloni. Estudo da competitividade de cadeias 
integradas no Brasil: impactos das zonas de livre comércio. Campinas: UNICAMP-IE-NEIT, 2002. p. 148-155.

GONZATTO, Marcelo; LISBOA, Sílvia. Decisão polêmica barateia remédio. Zero Hora, Porto Alegre, p. 12, 2007.

GUISE, Mônica Steffen. Comércio internacional e propriedade intelectual: limites ao desenvolvimento? In: BARRAL, Welber; PIMENTEL, Luiz Otávio. Propriedade intelectual e desenvolvimento. Florianopolis: Fundação Boiteux, 2007. p. 35-57.

HUNT, Paul; KHOSLA, Rajat. Acesso a medicamentos como um direito humano. Sur, Revista Internacional de Direitos Humanos, São Paulo, v. 5, n. 8, p. 100-121, 2008.

HUNT, Paul. Neglected diseases: a human rights analysis. France: WHO, 2007. (Special topics in social, economic and behavioural research report series, n. 6). Disponível em:

https://apps.who.int/iris/bitstream/handle/10665/43696/9789241563420_eng.pdf. Acesso em: 20 maio 2020.

IMPERIAL COLLEGE LONDON. Coronavirus (COVID-19) - updates and guidance. Imperial College London, London, 2020. Disponível em: https://www.imperial.ac.uk/about/covid-19/. Acesso em: 31 maio 2020.

INSTITUTO NACIONAL DA PROPRIEDADE INDUSTRIAL. Importância das patentes na área da saúde(medicamentos e vacinas): abril de 2020. [Rio de Janeiro]: INPI, 2020. Disponível em: https://inpi.justica.gov.pt/Portals/6/PDF\%20INPI/Not\%C3\%ADcias\%20-

\%20ficheiros\%20de\%20apoio/Import\%C3\%A2ncia\%20das\%20patentes\%20na\%20\%C3\%A1rea\% 20da\%20sa\%C3\%BAde\%20(medicamentos\%20e\%20vacinas).pdf?ver=2020-04-26-122645-213.

Acesso em: 28 maio 2020.

KUPFERSCHMIDT, Kai; COHEN, Jon. WHO launches global megatrial of the four most promising coronavirus treatments. Science, [S. I.], 2020. Disponível em:

https://www.sciencemag.org/news/2020/03/who-launches-global-megatrial-four-mostpromising-coronavirus-treatments. Acesso em: 28 maio 2020.

MACEDO, Maria Fernanda Gonçalves; PINHEIRO, Eloan dos Santos. O impacto das patentes farmacêuticas em países em desenvolvimento e as perspectivas para o Brasil. In: VARELLA, Marcelo Dias. Propriedade intelectual e desenvolvimento. São Paulo: Aduaneiras, 2005. p. 277-304.

MAIA, Catarina. Patentes e pandemia: entre licenças obrigatórias e responsabilidade social. Publico, Lisboa, 2020. Disponível em: https://www.publico.pt/2020/04/08/economia/opiniao/patentes-pandemia-licencasobrigatorias-responsabilidade-social-1911310. Acesso em: 30 maio 2020.

MINISTÉRIO DA SAÚDE (Brasil). Coronavírus COVID-19. [Brasília, DF]: Ministério da Saúde, 2020. Disponível em: https://coronavirus.saude.gov.br/. Acesso em: 31 maio 2020. 
MORAIS, José Luis Bolzan de; MORAIS, Eliane Pinheiro de. Direitos humanos e saúde. $\mathbf{O}$ mundo da saúde, São Paulo, v. 22, n. 2, p. 81-85, 1998.

NAVAS, Maria Helena. Coronavírus: as 6 potenciais vacinas contra covid-19 que já começaram testes em humanos. Viva Bem, [S. I.], 2020. Disponível em:

https://www.uol.com.br/vivabem/noticias/bbc/2020/05/01/coronavirus-as-6-potenciaisvacinas-contra-covid-19-que-ja-comecaram-testes-em-humanos.htm. Acesso em: 29 maio 2020.

NWOBIKE, Justice C. Empresas farmacêuticas e acesso a medicamentos nos países em desenvolvimento: o caminho a seguir. Sur, Revista Internacional de Direitos Humanos, São Paulo, v. 3, n. 4, p. 126-143, 2006.

PALMEIRA FILHO, P. L. et al. O desafio do financiamento à inovação farmacêutica no Brasil: a experiência do BNDES Profarma. Revista do BNDES, Rio de Janeiro, n. 37, p. 67-90, 2012.

PIMENTEL, Luiz Otávio. Direito industrial: as funções do direito de patentes. Porto Alegre: Síntese, 1999.

SCHWARTZ, G. 0 tratamento jurídico do risco no direito à saúde. Porto Alegre: Livraria do Advogado, 2004.

SERRANO, Claudia Freixinho; PINHO, Ágata. A Covid-19 e a corrida das empresas farmacêuticas para acabar com a pandemia: equilíbrio entre o interesse público e o interesse económico. Dinheiro Vivo, Lisboa, 2020. Disponível em: https://www.dinheirovivo.pt/opiniao/a-corridadas-farmaceuticas-para-o-fim-da-covid-19/. Acesso em: 30 maio 2020.

SHERWOOD, Robert M. Propriedade Intelectual e desenvolvimento econômico. São Paulo: EdUSP, 1992.

SILVERMAN, Ed. WHO is asked to create a voluntary intellectual property pool to develop Covid19 products. Statnews, [S. I.], 2020. Disponível em:

https://www.statnews.com/pharmalot/2020/03/24/covid19-coronavirus-costa-ricaintellectual-property/. Acesso em: 28 maio 2020.

TOMAZETTE, M. Curso de direito empresarial: teoria geral e direito societário. 6. ed. São Paulo: Atlas, 2012.

VARELLA, Marcelo Dias. Propriedade intelectual e desenvolvimento. São Paulo: Aduaneiras, 2005.

WALLERSTEIN, Immanuel. World-systems analysis: an introduction. London: Duke, 2006.

WORLD INTELLECTUAL PROPERTY ORGANIZATION. WIPO launches new search facility for patentscope database to support COVID-19 innovation efforts. Geneva: WIPO, 2020. Disponível em: https://www.wipo.int/pressroom/en/articles/2020/article_0008.html. Acesso em: 29 maio 2020. 
WORLD HEALTH ORGANIZATION. World health statistics 2018: monitoring health for the SDGs, sustainable development goals. Geneva: WHO, 2018.

WORLD HEALTH ORGANIZATION. "Solidarity" clinical trial for COVID-19 treatments. World Health Organization, [Geneva], 2020. Disponível em:

https://www.who.int/emergencies/diseases/novel-coronavirus-2019/global-research-on-novelcoronavirus-2019-ncov/solidarity-clinical-trial-for-covid-19-treatments. Acesso em: 29 maio 2020.

Recebido em: 01/06/2020

Aceito em: 02/06/2020 